\title{
Simulação de experimentos históricos no ensino de física: uma abordagem computacional das dimensões histórica e empírica da ciência na sala de aula \\ (Historical experiments simulations in physics education: a computational approach of the historical and empirical dimensions of science in classroom)
}

\author{
Luiz A. Ribeiro Junior ${ }^{\boxplus, 2}$, Marcelo F. Cunha² e Cássio C. Laranjeiras ${ }^{1,2}$ \\ ${ }^{1}$ Universidade de Brasília, Brasilia, DF, Brasil \\ ${ }^{2}$ Museu de Ciência e Tecnologia de Brasilia, Brasília, DF, Brasil \\ Recebido em 9/3/2011; Aceito em 24/5/2012; Publicado em 14/12/2012
}

\begin{abstract}
Neste trabalho propomos a utilização de simulações computacionais de experimentos históricos no ensino de física como estratégia de resgate e articulação das dimensões histórica e empírica da física na sala de aula. Como exemplo, apresentamos uma classe de simulação computacional didática, caracterizada aqui como Simulação Didática Interativa (SDI), utilizando o software Modellus para apresentar a experiência do plano inclinado proposta por Galileu Galilei(1564-1642) em sua obra Discursos e Demonstrações Matemáticas em Torno de Duas Novas Ciências (1638), onde a lei da queda dos corpos é investigada.
\end{abstract}

Palavras-chave: simulações computacionais, experimentos históricos, plano inclinado, Modellus.

In this paper we propose the use of computer simulations of historical experiments in physics education as a strategy to recover and articulate the historical and empirical dimensions of scientific knowledge in the classroom. Particularly, we present a Didactic Interactive Simulation (DIS) using the software Modellus to rescue the experiment of the inclined plane described by Galileo Galilei in his work Discourse and Mathematical Demonstrations Concerning Two New Sciences (1638), in which he investigates the law of falling bodies.

Keywords: computer simulations, historical experiments, inclined plane, Modellus.

\section{Introdução}

As ciências naturais são consideradas como ciências empíricas porque a experimentação tem um papel central no processo de produção de novos conhecimentos [1]. No entanto, a dimensão empírica enquanto constitutiva do conhecimento científico é quase sempre negligenciada, quando não deturpada, nas aulas de física. A exemplo do que acontece com os aspectos históricos e filosóficos, também geralmente concebidos como meros adereços motivacionais ao ensino da ciência, o papel da experimentação científica no processo de contrução do conhecimento permanece ocultado [2]. Em consequência disso estabelece-se uma compreensão equivocada da própria ciência que se pretende ensinar. Significativos esforços têm sido feitos nos últimos 30 anos para investigar e entender as ciências naturais como um trabalho de mentes, de mãos e como um processo social [1].

O grande potencial dos experimentos históricos como estratégia de resgate e articulação das dimensões

\footnotetext{
${ }^{1}$ E-mail: ribeirojr@fis.unb.br.

histórica e empírica da física no ensino vem sendo explorado na elaboração de recursos didáticos para o ensino de física [3-10]. Diferentes estudos nesta direção vem sendo conduzidos por pesquisadores de filosofia da ciência e de ensino de física nos últimos anos [11-15].

O Grupo de Pesquisa em Educação Superior e História da Ciência do Departamento de Física da Universidade de Oldenburg, Alemanha, desenvolve um projeto nesta direção utilizando réplicas de experimentos históricos para fins de ensino. Para Höttecke, a história da física e o trabalho com experimentos históricos replicados desempenham importante papel na formação de professores e estudantes, tornando compreensível o significado da experimentação na história da ciência [1].

Por experimentos históricos compreende-se aqui toda e qualquer tentativa bem sucedida em estabelecer um marco de referência conceitual e/ou metodológica na definição e/ou solução de um determinado problema especfíco. Entretanto, um elemento complicador para a utilização de um experimento histórico no ensino é sem dúvida o seu alto grau de dificuldade de reconsti- 
tuição física, envolvendo também diferentes campos do trabalho historiográfico. Além disso, os recursos que geralmente estão a disposição dos professores são muito limitados, o que torna a realização desses experimentos praticamente impossível. Isto acaba desestimulando o educador a reconstituir o experimento e demostrá-lo em sala de aula.

Uma alternativa que surge naturalmente como resultado do grande desenvolvimento de novas tecnologias computacionais é a simulação desses experimentos em ambiente computacional. Atualmente, simulações e modelagens de sistemas físicos em computador são amplamente usadas no ensino de física e permitem que o professor adapte a experiência didática de acordo com os objetivos de aprendizagem que pretende alcançar quando as utiliza [16-23]. Para fomentar esse uso, programas foram desenvolvidos com o intuito de serem o mais simples e natural de se programar [24]. Segundo Nogueira e cols. [25], em relação a física todas as séries apresentam tópicos que contemplam conceitos técnicos e cálculos, onde as situações virtuais criadas em ambiente computacional proporcionam uma ferramenta significativa para a aprendizagem desses conceitos. Além disso, Nogueira e seus colaboradores sugerem que a maioria dos softwares educacionais disponíveis possuem uma característica comum muito importante: Eles independem das concepções dos alunos que os utilizam, isto é, os mesmos são desenvolvidos para simular diferentes situações-problema como colisões, plano inclinado, oscilações, etc. Assim, esses softwares educacionais apresentam-se como alternativa para alunos com diferentes graus de desenvolvimento cognitivo e diferentes concepções em relação ao assunto abordado, respeitando as particularidades entre o variado grupo de usuários do software.

Apesar de simulações e modelagens no ensino de física serem largamente utilizadas, pesquisas sobre ferramentas de simulação em uma perspectiva mais ampla que envolva, não só a simulação como uma estratégia didática a ser utilizada pelo educador, mas também a interatividade do aluno com a ferramenta, encontram-se pobremente descritas na literatura. Viet e cols. discutem a importância da modelagem na relação ensino/aprendizagem de física na perspectiva dos Parâmetros Curriculares Nacionais para o Ensino Médio (PCNEM) [26] e sugerem a utilização da ferramenta computacional Modellus, que é um software educacional desenvolvido especialmente para a modelagem no ensino de ciências e matemática, para promover a conexão entre os assuntos de física ensinados em sala de aula e a perspectiva dos PCNEM. Assim, a utilização dessas ferramentas de modelagens seriam motivadas pela possibilidade de se tratar os problemas de física apresentados no ensino médio de maneira mais real e atual, fazendo da modelagem uma estratégia indispensável para uma mudança radical na maneira de se ensinar física nas escolas. Um outro estudo sobre mo- delagem computacional no ensino de física utilizando o software Modellus foi realizado por Araújo e cols. [27]. Nele foram analisadas as principais dificuldades na interpretação de gráficos de cinemática apresentadas pelos alunos através de um conjunto de atividades de modelagem computacional complementares às atividades tradicionais de ensino de cinemática. Araújo e cols. sugerem que o resultado mais importante do trabalho é a indicação da interatividade entre o aluno e o modelo computacional como o fator decisivo nas situações onde ocorreu aprendizagem. Isso indicou que a modelagem computacional poderia também contribuir para a consolidação de uma aprendizagem significativa.

Neste artigo sugerimos a utilização de simulações computacionais de experimentos históricos como estratégia de resgate e articulação das dimensões histórica e empírica da ciência em uma sala de aula de ensino médio. Para isso apresentaremos uma simulação computacional, utilizando o software Modellus, cujas características essenciais são apresentadas na seção a seguir. A experiência que escolhemos para modelarmos computacionalmente é a do plano inclinado retirada da obra Discursos e Demonstrações Matemáticas em torno de Duas Novas Ciências (1638), de Galileu Galilei(15641642). Escolhemos esse experimento pelo fato de o movimento de queda dos corpos ser causador de várias dúvidas entre os estudantes de ensino médio. Assim, o plano inclinado surge como um instrumento capaz de fornecer resultados importantes sobre a análise desse tipo de movimento, além de conter uma grande riqueza de detalhes históricos para serem explorados em sala de aula.

\section{O software Modellus}

Existem dois fatores relevantes que fazem da Simulação Didática Interativa (SDI) uma ferramenta importante para o desenvolvimento de estratégias didáticas no ensino de física: a animação do movimento em análise e a representação gráfica das grandezas físicas envolvidas no problema. Ambos possibilitam uma melhor compreensão dos aspectos físicos e matemáticos que envolvem o conceito em estudo. O termo interatividade, que utilizamos para classificar as simulações apresentadas neste trabalho, sugere basicamente que o estudante poderá modificar características dos elementos fundamentais que constituem a simulação, como por exemplo, o ângulo de inclinação do plano, a massa da esfera, etc. Nesse sentido, a utilização do software Modellus se mostrou a mais adequada por possuir uma interface gráfica, com objetos geralmente utilizados na representação de sistemas físicos e janelas de diálogo para entrada e saída de dados, que dispensa conhecimentos prévios de linguagem de programação por parte do usuário que desenvolverá a simulação. Isso permite que o educador se concentre apenas na descrição dos conceitos envolvidos no sistema que deseja simular. Uma outra ca- 
racterística importante do software Modellus é a sua portabilidade. A versão mais recente desse software foi desenvolvida utilizando a linguagem de programação Java, muito conhecida por permitir a construção com facilidade de elementos de interface gráfica e por ser compatível com todos os sistemas operacionais encontrados no mercado [17].

O software Modellus foi desenvolvido pelo professor Vitor D. Teodoro da Faculdade de Ciências e Tecnologia da Universidade Nova de Lisboa em Portugal, com o objetivo de permitir o desenvolvimento de simulações de fenômenos físicos a partir de equações diferenciais ou de funções que os representem, facilitando a construção de relações e significados, o que favorece a aprendizagem por parte dos estudantes [26]. No Modellus as equações são escritas praticamente com o mesmo simbolismo matemático que estamos acostumados escrever manualmente. Essa grande virtude faz desse software uma ferramenta de fácil aplicação no desenvolvimento de simulações de fenômenos físicos para serem implementados em uma aula de física no ensino médio. A Fig. 1 mostra os principais elementos da interface gráfica do software Modellus. A Fig. 1A mostra a janela Modelo onde são escritas as equações matemáticas e lógicas que descrevem o modelo. As simulações ocorrem na janela mostrada na Fig. 1B . Essa janela é responsável por mostrar o resultado final da simulação. Pode ocorrer de um mesmo arquivo conter mais de uma simulação, sendo possível escolher qual simulação executar selecionando o menu Casos. A barra de ferramentas dessa janela contém os objetos geralmente utilizados para a construção de simulações de fenômenos físicos. Assim, essa barra destina-se apenas a construção da simulação. A Fig. 1C mostra a janela Notas onde as informações pertinentes a simulação desenvolvida, escritas pelo educador, são mostradas ao usuário. A evolução temporal do sistema é controlada na janela Controlo, como mostra a Fig. 1D. Ao final do movimento, a tecla stop é acionada automaticamente. Movendo o cursor é possível retroagir o relógio e o movimento para executar a simulação novamente. Por último, a Fig. 1E mostra a janela Condições que deve ser utilizada quando a simulação exige que o usuário escolha o valor de um determinado parâmetro que sera empregado na mesma.

Levando em consideração todas as características descritas anteriormente sobre as facilidades do software Modellus e a importância da utilização das simulações computacionais como estratégia didática no ensino de física, é possível notar que esse software fornece ao educador uma excelente ferramenta computacional interativa para o processo de ensino/aprendizagem da física. Sob o foco educacional, o Modellus permite que o professor trabalhe com competências e habilidades fundamentais a serem desenvolvidas pelos alunos na disciplina de física no ensino médio. Entre elas estão o desenvolvimento da capacidade de investigação física, compreender enunciados que incluam códigos e símbolos físicos, utilizar tabelas, gráficos e relações matemáticas para expressar grandezas físicas, conhecer e utilizar conceitos físicos além de construir e analisar situações-problema [26]. Outras informações sobre o software Modellus como tutoriais de utilização voltado para educadores e download gratuito do software poderão ser encontrados em [28].

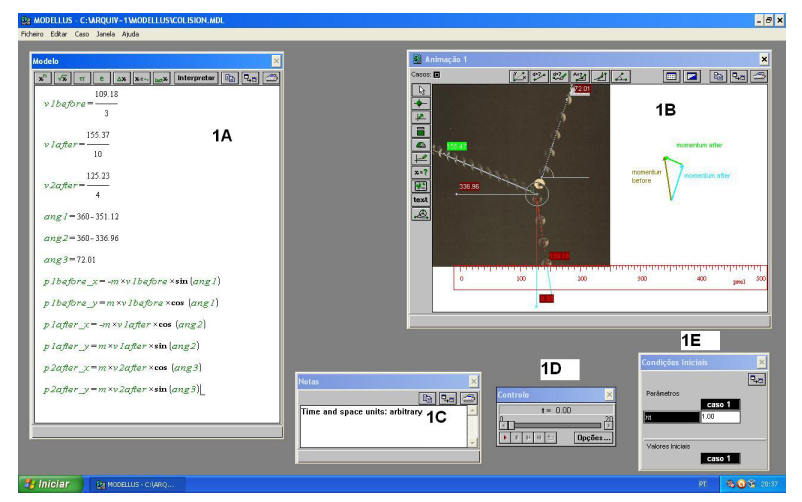

Figura 1 - Elementos principais da interface gráfica do software Modellus.

\section{O plano inclinado de Galileu}

Como exemplo de simulação didática interativa (SDI) utilizando o software Modellus apresentamos aqui a experiência do plano inclinado proposta por Galileu Galilei(1564-1642) em sua obra Discursos e Demonstrações Matemáticas em Torno de Duas Novas Ciências(1638), onde a lei da queda dos corpos é investigada. A riqueza de detalhes históricos contida neste episódio específico da obra de Galileu nos permitirá o resgate da dimensão histórica da ciência em articução com a dimensão empírica, revelando detalhes fundamentais do processo de desenvolvimento do conhecimento científico neste período.

Para compor sua análise sobre o movimento em um plano inclinado, Galileu utiliza seus estudos anteriores acerca da queda dos corpos, da geometrização do movimento e a lei dos números ímpares, do tempo e sobre a ação das forças dissipativas envolvidas no movimento. A seguir, apresentamos a análise do fenômeno de queda dos graves através do emprego do plano inclinado, segundo a sequência descrita na obra de Galileu [29].

\subsection{A queda dos corpos}

Para responder a questões acerca da queda dos corpos, Galileu utiliza recursos da geometria euclidiana, o emprego de experiências de pensamento e o estabelecimento de postulados. O objetivo de Galileu é analisar os movimentos naturalmente acelerados que tenham como princípio o entendimento de que novos acréscimos de velocidade devem ocorrer de acordo com uma proporção simples. Nas palavras de Galileu, 
Assim, qualquer que seja o número de partes iguais do tempo que tenha decorrido a partir do instante que o móvel abandona o repouso e começa a descer, o grau de velocidade adquirido na primeira e segunda parte e o tempo será o dobro do grau de velocidade adquirido pelo móvel na primeira parte; assim também, o grau que se obtém em três partes de tempo será o triplo e, na quarta parte, será o quádruplo de grau obtido na primeira parte. [29]

Usando o tempo como parâmetro, Galileu estabelece a noção correta de proporcionalidade que relaciona as grandezas velocidade e tempo. Esse conceito é utilizado em todos os outros estudos realizados por ele em [29]. Da forma moderna, essa afirmação de Galileu seria representada da seguinte maneira

$$
V \propto t .
$$

No entanto, Galileu apresenta a proporcionalidade de tempo em relação a velocidade geometricamente, como mostrando na Fig. 2. Galileu atribui dimensões físicas de velocidade, espaço e tempo que podem descrever tanto movimentos uniformes quanto movimentos acelerados. O movimento uniforme é descrito pelo retângulo CDEF, onde é possível notar que a velocidade, segmentos de reta horizontais dentro do retângulo, não aumentam com o tempo. Já no movimento acelerado, caracterizado pelo triângulo $\mathbf{C D H}$, percebe-se que a velocidade aumenta de maneira constante. Na Fig. 2 a notação $(*)$ foi colocada para facilitar a compreensão das grandezas físicas representadas na mesma. A Fig. 2 mostra geometricamente o Proposição I da obra de Galileu, que é enunciada da seguinte maneira:

O tempo no qual um determinado espaço é percorrido por um móvel que parte do repouso com um movimento uniforme acelerado é igual ao tempo no qual aquele mesmo espaço seria percorrido pelo mesmo móvel uniforme, cujo grau de velocidade seja metade do maior e último grau de velocidade alcançado no movimento uniformemente acelerado. [29]

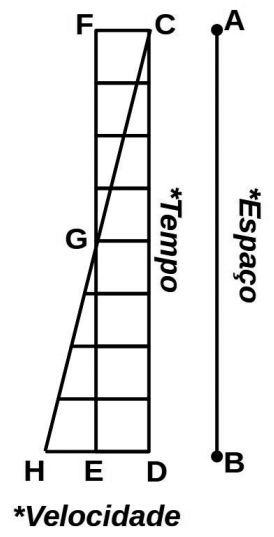

Figura 2 - Comparação entre movimento uniforme e movimento naturalmente acelerado utilizando elementos de geometria.

\subsection{A geometrização do movimento e a lei dos números ímpares}

Em sua busca por definir as grandezas espaço, tempo e velocidade, Galileu utiliza elementos geométricos para fazer uma análise um pouco mais detalhada do que a mostrada na Fig. 2. Para isso, ele subdivide o segmento AB em partes de mesmo tamanho que representam o espaço percorrido pelo móvel em um movimento naturalmente acelerado no intervalo de tempo CD como mostra a Fig. 3 .

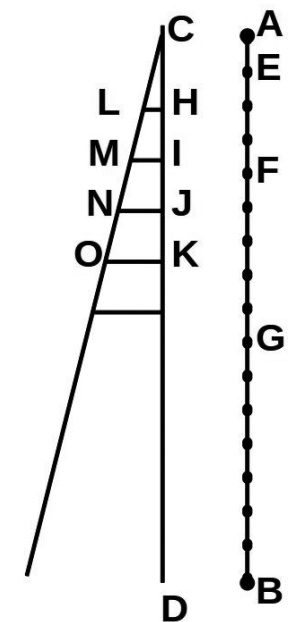

Figura 3 - Representação geométrica do movimento uniformemente acelerado de queda de um corpo a partir do repouso.

Essa dedução é mostrada por Galileu de maneira mais sintética na Proposição II de sua obra:

Se um móvel, partindo do repouso, cai com um movimento uniformemente acelerado, os espaços por ele percorridos em qualquer tempo estão entre si na razão dupla dos tempos,a saber, como os quadrados desses mesmos tempos. [29]

A proposição leva à chamada Lei dos Números Ímpares. Utilizando a notação moderna, a Proposição II pode ser expressa por

$$
s \propto t^{2} .
$$

Tanto a Proposição I quanto a proposição II estão corretas sob o ponto de vista da física clássica, sendo extraídas das observações de Galileu na geometrização do movimento como tentativa de entendê-lo. Nesse processo de análise do movimento de queda de um corpo, Galileu fez uma de suas observações mais importantes:

Afirmo que o espaço AF esta para o espaço AE numa proporção dupla daquela que o tempo CI tem para o tempo CH. [29]

Como o tempo $\mathbf{C I}$ é o dobro de $\mathbf{C H}$, o espaço $\mathbf{A F}$ deverá estar para o quádruplo de $\mathbf{A E}$. Esta dedução é melhor representada na Fig. 4, utilizando as medidas dos intervalos e a caracterização física das grandezas. 

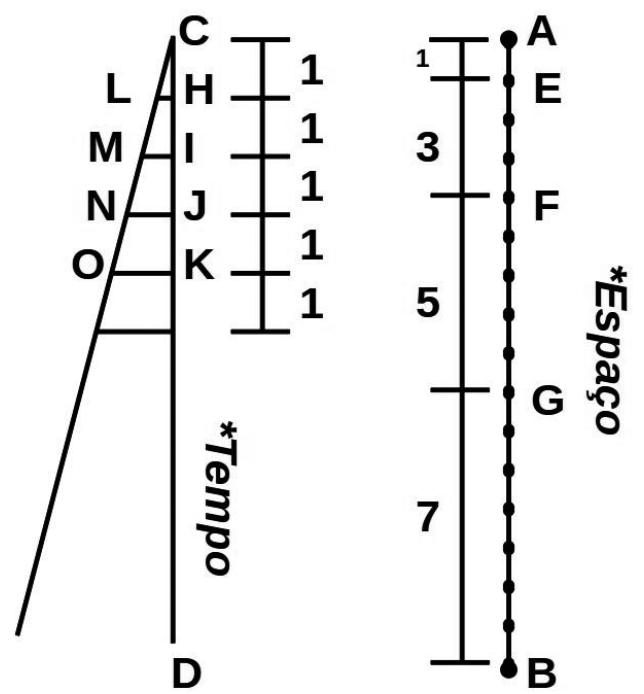

Figura 4 - Representação do significado físico dos segmentos de reta da Fig. 3.

Podemos notar da Fig. 4 que os espaços percorridos pelo móvel aumentam na proporção sugerida por Galileu, isto é, $\mathbf{C I}=2 \mathbf{C H}$ e $\mathbf{C K}=2 \mathbf{C I}$, para o tempo, assim como $\mathbf{A F}=4 \mathbf{A E}$ e $\mathbf{A B}=4 \mathbf{A F}$, para o espaço. Também é possível perceber que se partindo do primeiro instante fossem tomados intervalos de tempo iguais $(\mathbf{C H}$, HI, IJ, JK) nos quais se percorre, respectivamente, os espaços (AE, EF, FG, GB), estes estariam entre si como os números ímpares a partir da unidade, isto é, 1, $3,5,7$, o que caracteriza a lei dos números ímpares. Isso pode ser melhor visualizado com o auxílio da Tabela 1 que resume esse raciocínio a medida em que relaciona os espaços aos quadrados dos tempos [30].

Tabela 1 - Lei dos números ímpares consecutivos.

\begin{tabular}{lc}
\hline Tempo de queda & Espaço percorrido \\
1 & 1 \\
2 & $1+3=4$ \\
3 & $1+3+5=9$ \\
4 & $1+3+5+7=16$ \\
5 & $1+3+5+7+9=25$ \\
\hline
\end{tabular}

Tendo em vista essa relação de espaços, Galileu chega a seguinte conclusão:

[...] se tomarmos no seu conjunto os espaços percorridos podemos verificar que o espaço percorrido num tempo duplo é o quádruplo do percorrido no tempo simples, o espaço percorrido num tempo triplo é nove vezes o espaço percorrido no tempo simples, e, numa palavra, os espaços percorridos estão numa proporção dupla dos tempos, a saber, como os quadrados dos tempos. [29]

Podemos reescrever a Eq. (2) substituindo a relação de proporcionalidade por uma relação de igualdade utilizando uma constante $Z$,

$$
s=Z t^{2} \text {. }
$$

Fazendo $Z=\alpha / 2$, onde $\alpha$ é a aceleração do móvel, temos

$$
s=\frac{\alpha t^{2}}{2} .
$$

Podemos identificar claramente a Eq. (4) como um caso particular da função horária do movimento uniformemente variado, Eq. (5), como é denominada nos livros de física para o ensino médio, quando $s_{0}=0$ e $v_{0}=0$.

$$
s=s_{0}+v_{0} t+\frac{\alpha t^{2}}{2} \text {. }
$$

\subsection{O tempo como uma linha reta}

Na mecânica proposta por Galileu o tempo é definido geometricamente como uma dimensão do movimento e é tradado da seguinte maneira:

\begin{abstract}
"No que diz respeito à medida de tempo, empregávamos um grande recipiente cheio de água, suspenso no alto, o qual, por meio de uma pequeno orifício feito no fundo, deixava cair um fino fio de água, que era recolhido num pequeno copo durante todo o tempo em que a bola descia pela canaleta ou por suas partes. As quantidades de água assim recolhidas eram a cada vez pesadas com uma balança muito precisa, sendo as diferenças e proporções entre os pesos correspondentes às diferenças e proporções entre os tempos; e isto com tal precisão que, como afirmei, estas operações, muitas vezes repetidas, nunca diferiam de maneira significativa. [29]
\end{abstract}

Analisando esse fragmento da obra de Galileu fica claro que, apesar de o método ser teoricamente correto, o grande número de erros associados a esse processo de medida de tempo comprometem em muito os dados obtidos no experimento. Com isso, em relação a medida, a definição de tempo é um problema. Mais adiante, na mesma obra, Galileu chega a reconhecer a falha no processo de definição de tempo, mas infelizmente não deixa claro sua postura em relação a esse conceito.

\subsection{As forças dissipativas}

Em todos os experimentos descritos por Galileu exitem várias advertências em relação aos cuidados de se remover o que ele chama de "obstáculos acidentais". Na descrição de como realizar uma experiência com um plano inclinado, ele faz as seguintes observações:

Na verdade parece-me que esta suposição é tão provável que merece sem controvérsia, entendendo sempre que se removam todos os obstáculos acidentais e externos e que os planos sejam suficientemente sólidos e lisos 
e o móvel tenha uma forma perfeitamente esférica, de modo que tanto o móvel como o plano não possua asperezas [...] [29]

Já em relação as forças de arrasto, que ocorrem nos lançamentos de projéteis, Galileu estabelece:

Além disso, e tomando um pouco mais de liberdade, posso demonstrar-lhes através de dois experimentos que a pequena dimensão dos instrumentos por nós utilizados faz com que sejam apenas observáveis as resistências externas e acidentais, entre as quais a do meio é a mais considerável. Farei considerações sobre os movimentos ocorrem no ar, visto que aqueles de que falamos são desse tipo; contra esses movimentos, o ar oferece sua força de duas maneiras; uma consiste em oferecer maior resistência aos móveis menos pesados que aos móveis muito pesados; ao outra consiste em oferecer maior resistência à maior velocidade que à menor velocidade de um mesmo móvel. [29]

Com isso, Galileu deixa clara a relação de proporcionalidade entre a resistência do ar e a velocidade. Além disso, é possível notar que ele também mostra a diferença entre os movimentos de corpos distintos onde o menos pesado sofreria, proporcionalmente, uma resistência maior que o mais pesado, deixando claro que este argumento é valido para corpos constituídos de um mesmo material.

\subsection{O plano inclinado}

Galileu utiliza o plano inclinado baseado em duas grandes idéias. A primeira delas é que os movimentos de queda ocorrem com o aumento de velocidade do móvel a taxas constantes em intervalos de tempo iguais. A outra idéia vem da observação da relação entre o movimento vertical e um movimento ao longo de um plano inclinado, onde a dificuldade do estudo esta relacionada a inclinação do plano. Em relação a essas idéias Galileu afirma:

Portanto, o que foi demonstrado no referente às quedas verticais, também acontece do mesmo modo para os movimentos que se realizam em planos inclinados quaisquer; supusemos, com efeito, que em tais planos os graus de velocidade aumentam sempre na mesma proporção, ou seja, proporcionalmente ao tempo, ou ainda, segundo a simples série dos números inteiros. [29]

A Fig. 5, retirada da obra de Galileu [29], mostra os elementos geométricos que caracterizam o plano inclinado. Nela é possível observar três trajetórias para o corpo partindo do ponto $\mathbf{C}$, onde a velocidade final será a mesma independentemente do trajeto escolhido CA, CB ou CD.

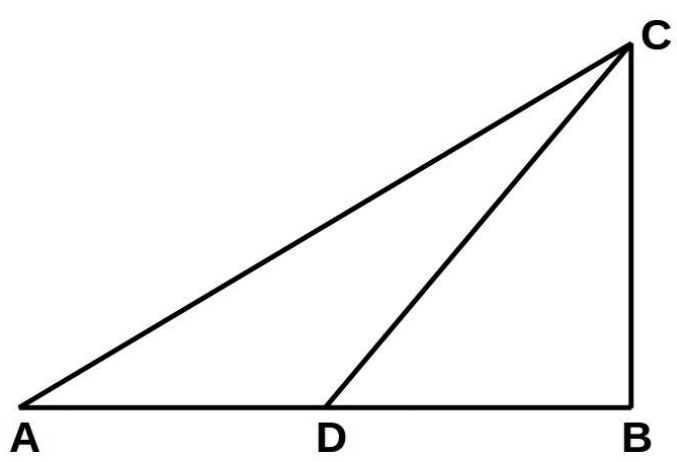

Figura 5 - Representação geométrica do plano inclinado de Galileu [29].

Apesar da simplicidade de sua construção, o plano inclinado representa uma ferramenta com enorme potencial de investigação. Acerca dessa simplicidade Galileu diz:

Numa ripa ou, melhor dito, numa viga de madeira com um comprimento aproximado de 12 braças, uma largura de meia braça um lado a três dedos no outro, foi escavada uma canaleta perfeitamente retilínea, para ficar bem polida e bem limpa foi colocada uma folha de pergaminho que era polida até ficar bem lisa; fazíamos descer por ele uma bola de bronze duríssima perfeitamente redonda e lisa. Uma vez construído o mencionado aparelho, ele era colocado em uma posição inclinada, elevando sobre o horizonte uma de suas extremidades até a altura de uma ou duas braças, e se deixava descer, como afirmei, a bola pela canaleta, notando como explorei mais adiante o tempo que empregava para descida completa; repetindo a mesma experiência muitas vezes para determinar a quantidade de tempo, na qual nunca se encontrava uma diferença nem mesmo da décima parte de uma batida de pulso. [29]

\section{Simulações}

Reconstituímos o experimento histórico do plano inclinado de Galileu segundo sua obra, Discursos $e$ Demonstrações Matemáticas em torno de Duas Novas Ciências, e também segundo uma reconstituição artística desse experimento pertencente ao Museu e Instituto de História da Ciência (IMSS), localizado em Florença na Itália, através de simulações computacionais utilizando o software Modellus. Aqui chamaremos a obra de Galileu citada acima de Discorsi, uma abreviação do título original. Com isso, o caráter experimental que a prática laboratório no ensino de física 
proporciona, cede espaço aos meios virtuais de aprendizagem, mantendo fidelidade ao fenômeno físico, pois as equações utilizadas para construção das simulações seguem os modelos científicos atualmente aceitos para a descrição desses fenômenos. A utilização dessas simulações exigem intervenções constantes do professor no intuito de se caracterizar uma prática que explore outras dimensões do experimento que não sejam a sua efetiva realização. Entendemos que essas simulações não serão aproveitadas de maneira correta se as mesmas forem inseridas em uma estratégia didática que não busque resgatar a dimensão empírica da ciência dentro de uma abordagem histórica da ciência. Nesse sentido, as simulações devem ser utilizadas de maneira articulada às abordagens textuais que geralmente são empregadas no ensino de história da ciência.

\subsection{O plano inclinado de Galileu segundo os Discorsi}

A simulação do plano inclinado segundo os Discorsi tem como objetivo despertar a percepção dos alunos em relação a sua utilização como ferramenta para o estudo dos fenômenos envolvidos na queda dos corpos. Nessa simulação o aluno tem controle sobre todo o movimento da esfera no plano, podendo obter a posição da esfera utilizando uma régua ou extraindo a informação diretamente do campo de leitura da variável posição. Já o instante de tempo é representado pela massa de água contida no recipiente, que é diretamente proporcional ao volume, obtido no campo destinado a mostrar o valor da varável volume. É interessante chamar a atenção dos alunos para o fato de que esse experimento, desenvolvido por Galileu utilizando recursos experimentais bem limitados, proporcionou conclusões muito importantes.

A Fig. 6 mostra a interface do software Modellus com os detalhes dessa simulação.

Sugerimos que a maneira como Galileu explora os aspectos do plano inclinado deva ser apresentada em paralelo a essa simulação. Assim, utilizando elementos de geometria, Galileu faz uma modificação na Fig. 5 para incluir uma marca, representada pelo ponto $\mathbf{E}$ na Fig. 7, onde o tempo gasto pelo móvel para percorrer a distância CE seria o mesmo gasto na queda livre $\mathbf{C B}$. Nas palavras de Galileu:

[... o móvel no mesmo tempo em que percorrer o espaço vertical $\mathbf{C B}$, precorrerá também o espaço $\mathbf{C E}$ no plano inclinado CA, sendo os momentos com espaço, e o grau de velocidade em $\mathbf{B}$ estará para o grau de velocidade em $\mathbf{E}$ na mesma proporção que existe CB e CE. [29]

Com isso, Galileu mostra a que CE é a terceira proporcional de $\mathbf{C A}$ e $\mathbf{C B}$ em relação ao plano inclinado CA. O significado geométrico dessa relação é

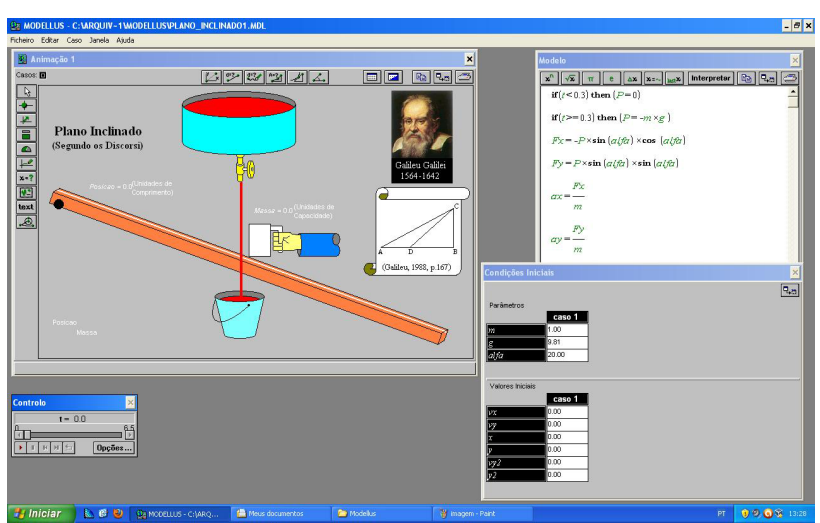

Figura 6 - Simulação do plano inclinado de Galileu segundo os Discorsi [29].

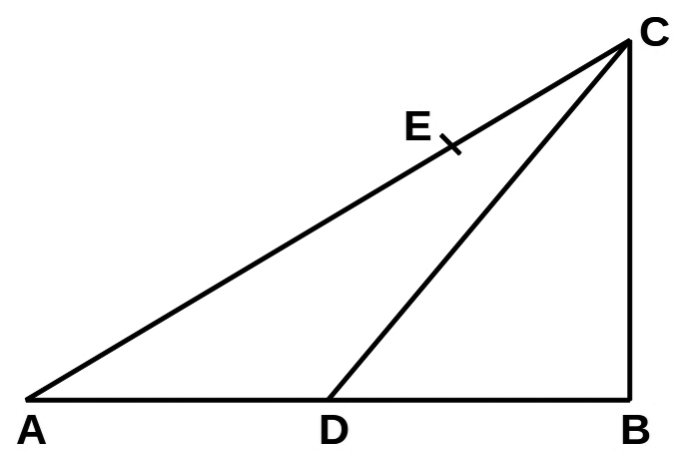

Figura 7 - Plano inclinado de Galileu segundo os Discorsi [29].

$$
C E=\frac{C B^{2}}{C A}
$$

Ele mostra também que podemos escrever CE como a média proporcional entre $\mathbf{C A}$ e $\mathbf{C E}$, que pode ser expressa por

$$
C B=\sqrt{C E \times C A} .
$$

Nesse caso, podemos situar geometricamente o ponto $\mathbf{E}$ no plano inclinado $\mathbf{C A}$ de forma que o triângulo $\mathbf{A B C}$ seja semelhante ao triângulo BCE. Com isso, uma característica importante do plano inclinado vem a tona, isto é, o movimento ao longo de $\mathbf{C B}$ ocorre nos mesmo intervalo de tempo de $\mathbf{C E}$, que é um movimento mais fácil de estudar, pelo fato de a velocidade do móvel em CE ser menor do que em CB. A Fig. 8 ilustra a configuração geométrica do plano inclinado com a escolha de localização do ponto $\mathbf{E}$ descrita acima.

O fragmento retirado dos Discorsi descreve a maneira pela qual Galileu construiu o experimento, fazendo referência também ao seu funcionamento. 


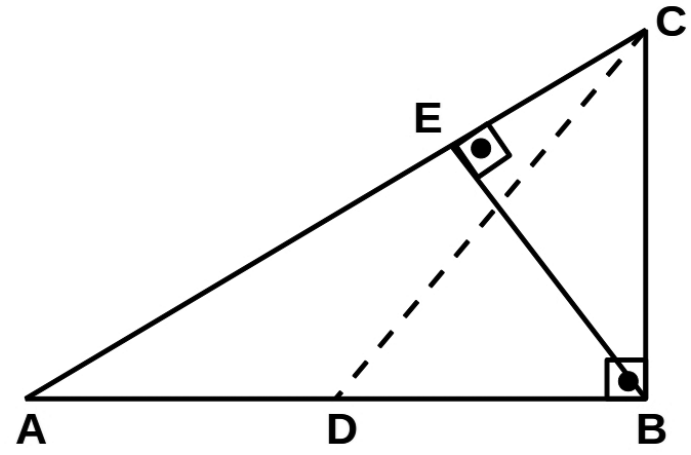

Figura 8 - Plano inclinado de Galileu segundo os Discorsi [29].

[...] Numa ripa ou, melhor dito, numa viga de madeira com um comprimento aproximado de 12 braças, uma largura de meia braça um lado a três dedos no outro, foi escavada uma canaleta perfeitamente retilínea, para ficar bem polida e bem limpa foi colocada uma folha de pergaminho que era polida até ficar bem lisa; fazíamos descer por ele uma bola de bronze duríssima perfeitamente redonda e lisa. Uma vez construído o mencionado aparelho, ele era colocado em uma posição inclinada, elevando sobre o horizonte uma de suas extremidades até a altura de uma ou duas braças, e se deixava descer, como afirmei, a bola pela canaleta, notando como explorei mais adiante o tempo que empregava para descida completa; repetindo a mesma experiência muitas vezes para determinar a quantidade de tempo, na qual nunca se encontrava uma diferença nem mesmo da décima parte de uma batida de pulso. Feita e estabelecida com precisão tal operação, fizemos descer a mesma bola apenas por uma quarta parte do comprimento total da canaleta; e, medido o tempo de queda, resultava ser sempre rigorosamente igual à metade do outro, Variando a seguir a experiência e comparando o tempo requerido para percorrer todo o comprimento com o tempo requerido para percorrer a metade, ou os dois terços, ou os três quartos, ou para concluir qualquer outra fração, por meio de experiências repetidas mais de cem vezes, sempre se encontrava que os espaços percorridos estavam entre si como os quadrados dos tempos e isso em todas as inclinações do plano, ou seja, da canaleta, pela qual se fazia descer a bola. Observamos também que os tempos de queda para as diferentes inclinações do plano mantinham exatamente entre si a proporção que, como veremos mais adiante, foi encontrada e demonstrada pelo autor. No que diz respeito à medida do tempo, empregávamos uma grande recipiente cheio água, suspenso no alto, o qual, por meio de um pequeno orifício feito no fundo, deixava cair um fino fio de água, que era recolhido num pequeno copo durante todo o tempo em que a bola descia pela canaleta ou por suas partes. As quantidades de água assim recolhidas eram a cada vez pesadas com uma balança muito precisa, sendo as diferenças e proporções entre os pesos correspondentes às diferenças e proporções entre os tempos; e isto com tal precisão que, como afirmei, estas operações, muitas vezes repetidas, nunca diferiam de maneira significativa. [29]

A Fig. 9 mostra a janela de simulação do experimento ampliada. Nela procuramos mostrar os detalhes retirados do fragmento da obra de Galileu mostrado acima. Além disso, essa simulação contém uma janela de diálogo com o aluno onde os parâmetros podem ser controlados para possibilitar uma análise qualitativa do experimento quando diversas condições iniciais de simulação são comparadas. O gráfico da posição em função da massa de água é mostrado no canto inferior esquerdo da janela, o que possibilita a análise gráfica da posição em função do tempo de acordo com o experimento descrito nos Discorsi.

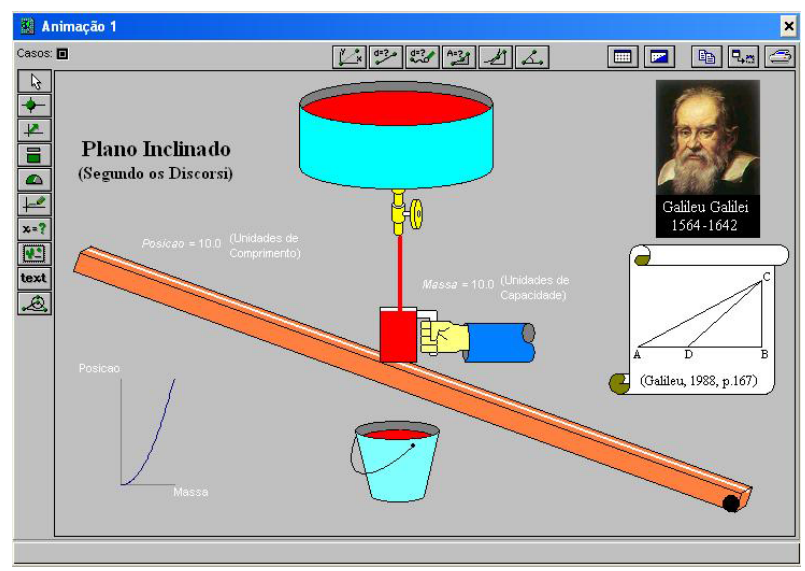

Figura 9 - Janela de simulação do plano inclinado de Galileu segundo os Discorsi [29].

\subsection{O plano inclinado de Galileu (IMSS)}

A simulação do plano inclinado de Galileu baseada na reprodução artística do experimento presente no IMSS tem como objetivo explorar a Lei dos Números Ímpares consecutivos e suas consequências. Nessa simulação, o aluno também pode controlar todo o movimento do móvel. Ao final da simulação, é possível perceber que a esfera percorre espaços cada vez maiores em tempos iguais, ou seja, os espaços são relacionados com período de oscilação do pêndulo. Essa simulação, embora parecida com a anterior, tem como característica didática a exploração de dois elementos importantes da obra de 
Galileu: o isocronismo do pêndulo e a Lei dos Números Ímpares. A Fig. 10 mostra a reconstituição do plano inclinado de Galileu em exposição no IMSS. Já a Fig. 11 destaca um dos sinos dispostos ao longo do trilho com espaçamento que obedece a Lei dos Números Ímpares.

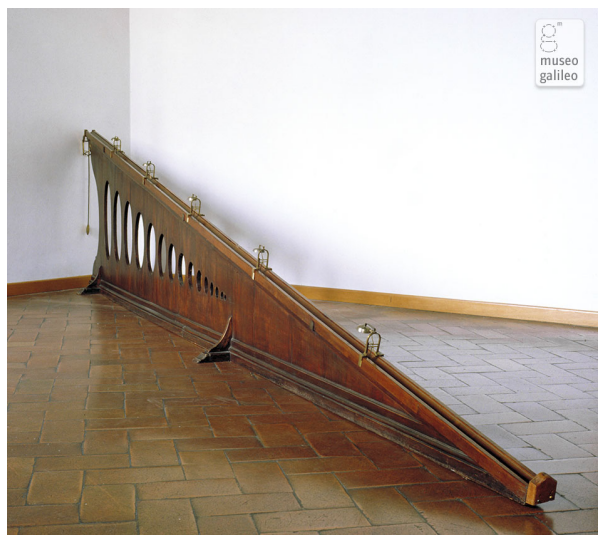

Figura 10 - Reconstituição do plano inclinado de Galileu presente no IMSS retirada da Ref. [32].

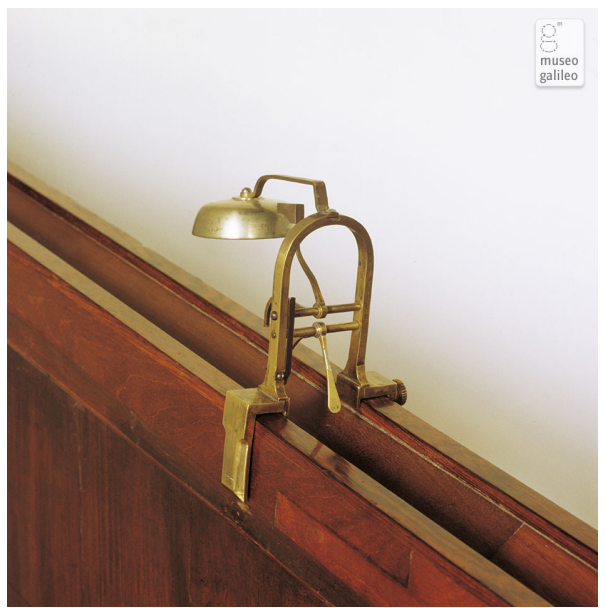

Figura 11 - Sino de trilho, com um pêndulo, que detecta a passagem da esfera, retirada da Ref. [32].

Embora esses dois elementos em destaque na Fig. 11 não sejam citados por Galileu, os mesmos funcionam como uma eficiente ferramenta didática. A simulação construída para reproduzir o plano inclinado de Galileu do IMSS é mostrada na Fig. 12.

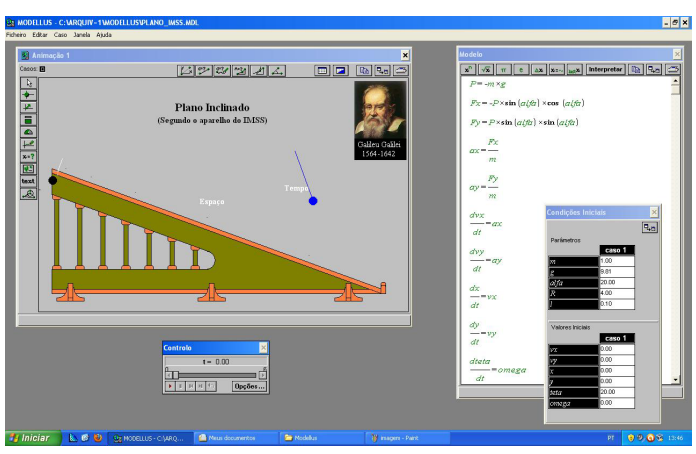

Figura 12 - Simulação do plano inclinado de Galileu segundo o IMSS [32].
A Fig. 13 mostra a janela de simulação onde é possível observar de forma clara considerando intervalos de tempo iguais, os espaços percorridos são proporcionais aos quadrados dos tempos, como mostrado na Eq. (2). Se forem consideradas as distâncias percorridas a cada 1/2 oscilação do pêndulo, será possível observar que estas distâncias obedecerão a série dos números ímpares. Empregamos o movimento estreboscópico tanto para o pêndulo quanto para a esfera para evidenciar essas relações.

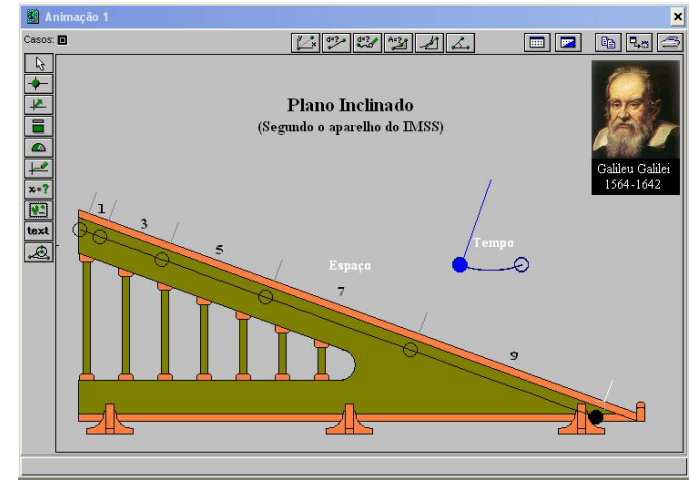

Figura 13 - Janela de simulação do plano inclinado de Galileu segundo o IMSS [32].

Utilizando essa simulação podemos também fazer uma análise física do movimento da esfera sob um trilho. Considerando essa esfera como um ponto material que desliza sem rolamento, as únicas forças envolvidas no sistema são: a força Penso $(\mathbf{P})$, ou as suas componentes tangente $\left(\mathbf{P}_{x}\right)$ e normal $\left(\mathbf{P}_{y}\right)$ ao plano inclinado e a força de reação $\left(\mathbf{F}_{N}\right)$. A Fig. 14, geralmente encontrada na maioria dos livros de física de ensino médio, mostra essa análise vetorial do movimento.

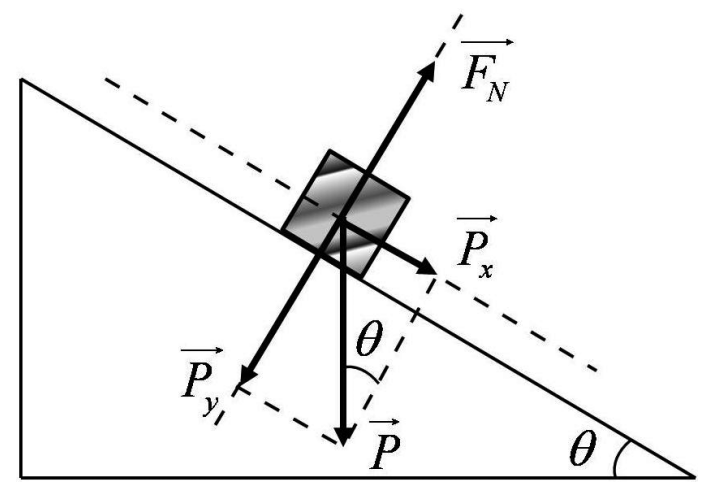

Figura 14 - Forças envolvidas na interação entre um corpo cúbico e um plano inclinado sem atrito.

\section{Conclusão}

Neste trabalho sugerimos a implementação de Simulações Didáticas Interativas (SDI) de experimentos históricos como uma estratégia didática para o ensino de física visando o resgate das dimensões histórica e empírica do conhecimento científico na sala de aula. 
Particularmente, desenvolvemos duas simulações, utilizando o software Modellus, resgatando a experiência do plano inclinado retirada da obra Discursos e Demonstrações Matemáticas em torno de Duas Novas Ciências (1638), de Galileu Galilei (1564-1642), onde o fenômeno de queda dos corpos é analisado. Entendemos que a confrontação do senso comum com os resultados obtidos pela simulação dos experimentos possibilita a superação de obstáculos de natureza epistemológica, proporcionando a apreensão dos conceitos físicos abordados e criando elementos mediadores capazes de estabelecer um diálogo direto do indivíduo com a dimensão histórica dos conceitos físicos envolvidos no experimento simulado computacionalmente. Acreditamos ainda que esse trabalho articulado entre as dimensões histórica e empírica da ciência contribui para o rompimento da tradicional percepção dessas dimensões como meros adereços ao trabalho didático-pedagógico com a ciência, situando-os como efetivas dimensões constitutivas da ciência.

\section{Agradecimentos}

Os autores agradecem a CAPES e o CNPq e pelo apoio no desenvolvimento deste trabalho.

\section{Referências}

[1] Dietmar Höttecke, Science \& Education 9, 343 (2000).

[2] Cássio C. Laranjeiras, in: Física Ainda é Cultura?, org. André Ferrer P. Martins (Editora Livraria da Física, São Paulo, 2009).

[3] André Ferrer P. Martins, Caderno Brasileiro de Ensino de Física 24, 112 (2007).

[4] Andreia Guerra, José Claudio Reis e Marco Braga, Caderno Brasileiro de Ensino de Física 21, 224 (2004).

[5] Adriana P. Gallego Torres e Romulo G. Badillo, Ciência \& Educação 13, 85 (2007).

[6] Verónica Guridi y Irene Arriassecq, Ciência \& Educação 10, 307 (2004).

[7] Jenaro Guisasola, Antonio Montero y Manuel Fernández, Revista Brasileira de Ensino de Física 30, 1604 (2008).

[8] M. Achilles, Historische Versuche der Physik: funktionstüchting nachgebaut (Heidelber, Berlin, 1989).

[9] Teichmann, J. Der Physikunterricht 17, 84 (1983).

[10] H.J. Wilke, Historische physikalische Versuche, Köln (Aulis Verlag Deubner \& Co, Köln, 1987).

[11] Adriana P. Gallego y Torres R. Gallego Badillo, Ciência \& Educação 13, 85 (2007).
[12] José Plínio Baptista, Revista Brasileira de Ensino de Física 28, 541 (2006).

[13] Fábio L.A. Pena e Aurino Ribeiro Filho, Caderno Brasileiro de Ensino de Física 26, 48 (2009).

[14] Andreia Guerra, José Claudio Reis e Marco Braga, Caderno Brasileiro de Ensino de Física 26, 48 (2009).

[15] José Lourenço Cindra, Revista Brasileira de Ensino de Física 30, 3601 (2008).

[16] Giuseppi Camilleti e Laércio Ferracioli, Revista Brasileira de Ensino de Física 24, 110 (2002).

[17] Jalves S. Figueira, Revista Brasileira de Ensino de Física 27, 613 (2005).

[18] Mariana Rampinelli e Laércio Ferracioli, Caderno Brasileiro de Ensino de Física 23, 93 (2006).

[19] Ademir L. Xavier Jr., Revista Brasileira de Ensino de Física 29, 241 (2007).

[20] Pedro F.T. Dorneles, Ives S. Araujo e Eliane A. Veit, Revista Brasileira de Ensino de Física 28, 487 (2006).

[21] Pedro F.T. Dorneles, Ives S. Araujo e Eliane A. Veit, Revista Brasileira de Ensino de Física 30, 3308 (2008).

[22] Antônio F. Licarião Nogueira, Revista Brasileira de Ensino de Física 30, 4306 (2008).

[23] Carlos Fiolhais e Jorge Trindade, Revista Brasileira de Ensino de Física 25, 259 (2003).

[24] Josiel R. Silva1, José S.E. Germano e Roni S. Mariano, Revista Brasileira de Ensino de Física, (33), 1508 (2011).

[25] José de Souza Nogueira, Carlos Rinaldi, Josimar M. Ferreira e Sérgio R. de Paulo, Revista Brasileira de Ensino de Física 22, 517 (2000).

[26] Eliane A. Veit e V.D. Teodoro, Revista Brasileira de Ensino de Física 24, 87 (2002).

[27] Ives S. Araújo, Eliane A. Veit e Marco A. Moreira, Revista Brasileira de Ensino de Física 26, 179 (2004).

[28] Modellus webpage, Disponível em http://modellus. fct.unl.pt/, acesso em 9/3/2011.

[29] Galileu Galilei, Duas Novas Ciências (Nova Stella, São Paulo, 1988).

[30] Marco C. Neves, De Experimentos, Paradigmas e Diversidade no Ensino de Física: Construindo Alternativas (Editora Massoni, Maringá, 2005).

[31] Ronaldo C. de Oliveira Paula, O Uso de Experimentos Históricos no Ensino de Física: Integrando as Dimensões Histórica e Empírica da Ciência na Sala ee Aula. Dissertação de Mestrado, Universidade de Brasília, 2006.

[32] Institute and Museum of the History of Science webpage. Disponível em http://catalogue. museogalileo.it/object/InclinedPlane.html, acesso em $9 / 3 / 2011$. 